\title{
Concepções de Adolescência e Educação na Atuação de Profissionais do CAPSi
}

\author{
Heloiza Iracema Luckow \\ Universidade da Região de Joinville, SC, Brasil
}

\author{
Aliciene Fusca Machado Cordeiro \\ Universidade da Região de Joinville, SC, Brasil
}

Resumo: O objetivo do estudo aqui apresentado foi apreender as concepções sobre adolescência e educação dos profissionais do Centro de Atenção Psicossocial Infanto-Juvenil (CAPSi) que embasam sua atuação, em especial aquela que se desenvolve junto ao processo de escolarização dos adolescentes que frequentam esse serviço. Foram entrevistados 11 profissionais que atuam em um CAPSi: uma assistente social, um psiquiatra, duas psicólogas, duas enfermeiras, quatro terapeutas ocupacionais e a coordenadora. Para a tessitura dos dados, adotou-se a análise de conteúdo, considerando alguns pressupostos da abordagem epistêmica-metodológica do materialismo histórico e dialético. As discussões e resultados apontam que, mesmo compreendendo a importância de seu trabalho junto ao adolescente com histórico de doença mental, os profissionais entrevistados demonstram dificuldade em romper com uma visão naturalizada de adolescência, que a entendem como uma fase de conflito e que dificultam a compreensão de ser essa uma parte do desenvolvimento constituída e significada pela própria sociedade. Evidenciou-se que trabalhar com esses adolescentes propicia aos profissionais da saúde refletir sobre o processo de escolarização, percebendo a valorização da escola no projeto terapêutico do adolescente, bem como a importância do envolvimento dos profissionais da área da saúde, da escola e da família, de forma a auxiliar para que o adolescente possa construir, com base em uma educação emancipatória, sua identidade e autonomia.

Palavras-chave: Educação, CAPSi, Adolescência, Escolarização.

\section{Conceptions of Adolescence and Education in the Professional Practice of CAPSi}

Abstract: The purpose of the study was to understand the concepts of adolescence and education that support the work - especially the work related to the schooling of adolescents - of the professionals that compose the Psychosocial Care Center for Children and Youth (CAPSi). 11 professionals who work in a CAPSi were interviewed: a social worker, a psychiatrist, two psychologists, two nurses, four occupational therapists and the coordinator. Content analysis was used for data analysis, considering some assumptions of the epistemic-methodological approach of the historical and dialectical materialism. The discussions and results show that, even understanding the importance of their work with adolescents with mental illness history, the professionals interviewed demonstrate difficulty in breaking the naturalized vision of adolescence, which understands it as a phase of conflict and neglects that it is a part of the development that is made and signified by the society itself. It was revealed that working with these adolescents makes health professionals reflect on the process of education and perceive school's importance in the therapeutic project of the adolescents as well as the importance of the involvement of school, family and theirs so that adolescents can build, based on an emancipatory education, an own identity and autonomy.

Keywords: Education, CAPSi, Adolescence, Schooling. 


\title{
Concepciones de Adolescencia y Educación en la
}

\section{Actuación de Profesionales del CAPSi}

\begin{abstract}
Resumen: El objetivo del estudio fue aprehender las concepciones sobre adolescencia y educación en las que se basa la actuación -especialmente la relacionada con el proceso de escolarización de adolescentes- de los profesionales del Centro de Atención Psicosocial Infantojuvenil (CAPSi). Fueron entrevistados 11 profesionales que actúan en un CAPSi: una asistente social, un psiquiatra, dos psicólogas, dos enfermeras, cuatro terapeutas ocupacionales y la coordinadora. Para el análisis de los datos, se adoptó una análisis de contenido, considerando algunos presupuestos del abordaje epistémico metodológico del materialismo histórico y dialéctico. Las discusiones y resultados apuntan que, aun comprendiendo la importancia de su trabajo al lado de los adolescentes con históricos de enfermedad mental, los profesionales entrevistados demuestran dificultad en romper con la visión naturalizada de adolescencia que entiende este periodo como una fase de conflicto, mientras ignora que es una parte del desarrollo constituida y significada por la propia sociedad. Se evidenció que trabajar con los adolescentes hace que los profesionales de la salud reflexionen sobre el proceso de escolarización y valoren a la escuela en el proyecto terapéutico del adolescente, percibiendo la importancia que tienen la escuela, la familia y ellos mismos para que el adolescente pueda construir, con base en una educación emancipadora, su identidad y autonomía.
\end{abstract}

Palabras clave: Educación, CAPSi, Adolescencia, Enseñanza.

\section{Introdução}

A escola do século XXI no Brasil tem sido convocada, ao menos no discurso, a realizar a inclusão educacional de todas as crianças, adolescentes e jovens, independentemente de sua classe social, etnia, gênero e das demais condições que os caracterize naquele momento. No entanto, frequentemente "faz-se uma inclusão excludente" (Veiga-Neto, \& Lopes, 2011, p. 122), na qual muitos estudantes conquistaram "o direito de entrar pelos portões da escola, mas ainda não conseguiram, apesar de toda sua resistência, de sua teimosia em querer aprender, derrotar o caráter excludente da escola brasileira” (Moysés, 2001, p. 10).

Assim, aqueles que não aprendem, não se comportam, não se enquadram nos padrões da escola, se encaixam no estigma de ser inadequado para o processo de escolarização. A responsabilidade pela desistência da escola, seja ela factual ou subjetivada, é discretamente - ou escancaradamente - transferida para a criança e/ou sua família. Individualiza-se dessa forma uma questão que é social, pois, de acordo com Meletti (2013), para se debater a inclusão é necessário compreender que a escola está inserida em uma sociedade sustentada pelo modo de produção capitalista, o qual tem em sua gênese o processo de exclu- são, ou melhor dizendo, de inclusão precária e instável, marginal (Martins, 2003).

Com a escola constituída em um contexto histórico e cultural predominantemente excludente e meritocrático, Meira (2003, p. 26). destaca que ela "apresenta-se para a sociedade praticamente como uma vítima de uma clientela inadequada e despreparada". Mas as dicotomias normal/anormal; apto/não apto; certo/errado não estão somente no âmbito da escola, pois, como já discutido, a escola constitui-se em consonância com a sociedade na qual está inserida.

Dentre os vários encontros possíveis nesse cenário, destaca-se neste estudo o encontro entre a Saúde e a Educação por meio de um objeto de pesquisa que pode ampliar e revelar como se formatam as relações do (não) aprender na escola e da doença mental em adolescentes. $\mathrm{O}$ trabalho aqui apresentado adentrou a área de saúde, especificamente o Sistema Único de Saúde (SUS) com o objetivo de apreender as concepções sobre adolescência e educação dos profissionais do Centro de Atenção Psicossocial Infanto-Juvenil (CAPSi) que embasam sua atuação, em especial aquela que se desenvolve junto ao processo de escolarização dos adolescentes que frequentam o CAPSi. 


\section{Adolescência e saúde mental: diálogos necessários}

A estratégia utilizada pelo SUS na "atenção à saúde para pessoas com sofrimento ou transtorno mental e com necessidades decorrentes do uso de crack, álcool e outras drogas" é a Rede de Atenção Psicossocial (Brasil, 2011). Em especial, na atenção à saúde mental de crianças e adolescentes, foi apenas no início do século XXI que esse público começou a sair da invisibilidade no Brasil. Dentre as propostas de intervenção, o CAPSi é a primeira ação concreta que compõe o cuidado de crianças e adolescentes com questões ligadas à saúde mental (Couto, \& Delgado, 2015).

O trabalho do CAPSi é destinado ao "serviço ambulatorial de atenção diária destinado a crianças e adolescentes com transtornos mentais" (Brasil, 2002, p. 5), tendo como principais atividades, conforme relatado na Portaria/GM no 336/2002,

[...] a - atendimento individual [...]; b - atendimento em grupos [...]; c - atendimento em oficinas terapêuticas [...]; d - visitas e atendimentos domiciliares; e - atendimento à família; f - atividades comunitárias enfocando a integração da criança e do adolescente na família, na escola, na comunidade ou quaisquer outras formas de inserção social; g - desenvolvimento de ações intersetoriais, principalmente com as áreas de assistência social, educação e justiça (grifos nossos).

Desse modo, entende-se a relevância de apreender a concepção que os profissionais do CAPSi têm com relação à adolescência e educação e de como essas concepções influenciam sua atuação, em especial aquela que se desenvolve junto ao processo de escolarização dos adolescentes que frequentam o CAPSi. Sabe-se que nossa sociedade é permeada por diferentes concepções de adolescência, por causa de distintas bases epistemológicas, sendo que a mais difundida é a que provêm de uma visão liberal, legitimada historicamente por uma ciência positivista, constituída por saberes da teologia, da filosofia, da Psicologia e das ciências sociais (Ozella, 2002). Essa visão hegemônica, descontextualizada e individualizante, caracteriza esse período da adolescência como um momento de dificuldades, conflitos e transformações, de modo que as condições sociais, culturais, históricas e psicológicas são relegadas a um segundo plano ou mesmo negligenciadas.

Contrária a essa visão, que concebe a adolescência como uma fase inerente ao desenvolvimento do homem dissociada da realidade na qual está inserido, destaca-se a necessidade de se olhar para a adolescência como um processo dialético, que se constrói historicamente, que considere o contexto no qual o adolescente se desenvolve e se constitui como sujeito. Nessa perspectiva, a adolescência é entendida como "um momento significado, interpretado e construído pelos homens" (Ozella, \& Aguiar, 2008, p. 104) e é constituída e significada pela própria sociedade, assim, cada indivíduo a vivencia de maneira singular.

A adolescência deve ser compreendida a partir do contexto no qual ela vem sendo construída, qual seja, uma sociedade que transforma essa fase em um fenômeno patológico e à margem da medicalização ${ }^{1}$, "uma sociedade que adoece cotidianamente, dadas as condições concretas de existência da população, seja pelas questões socioeconômicas, seja pela violência em todas as suas formas" (Fonseca, \& Ozella, 2010, p. 418).

Nesse sentido, Vicentim (2006) destaca que a adolescência é alvo da patologização, uma vez que o mundo adolescente é visto prioritariamente como objeto de falha, disfunção ou anomia. Assim, a sociedade e a cultura acabam servindo para fomentar a crise dos adolescentes, projetando neles seus próprios conflitos (Bock, 2007), de modo que "a manutenção das concepções de adolescência como um período naturalmente de crise cumpre o papel ideológico de camuflar a realidade, as contradições sociais, as verdadeiras mediações que constituem tal fenômeno" (Ozella, \& Aguiar, 2008, p. 100). Por isso, diferentemente de uma visão liberal, na qual o homem é concebido como natureza humana, a visão histórico-cultural contribui para a "despatologização" do desenvolvimento humano.

$\mathrm{O}$ adolescente no Brasil tem direitos assegurados por meio do Estatuto da Criança e do Adolescente, Lei n.o 8.069, de 13 de julho de 1990, sendo sujeito de direitos e responsabilidades, "dentre os quais se situa o direito ao cuidado. Mas, a noção de sujeito implica

\footnotetext{
${ }^{1}$ Entende-se o processo de medicalização da vida como um deslocamento de "problemas coletivos para a esfera do individual; problemas sociais e políticos para o campo médico", fato que promove a biologização e a naturalização de problemas que fazem parte do cotidiano dos indivíduos (Moyses, 2001, p. 14).
} 
também a de singularidade, que impede que esse cuidado se exerça de forma homogênea, massiva e indiferenciada" (Brasil, 2005, p. 11).

Esse cuidado, pensado a partir da particularidade da constituição de cada sujeito, engloba tanto a educação quanto a saúde. Na educação, o processo é especialmente desafiante, uma vez que, como repercussão da democratização do acesso à escola, ficaram mais explícitas as desigualdades sociais (Alves, \& Canario, 2004). Conforme Canário (2004, p. 64), esse fato levou "a impôr processos uniformes de ensino que conduzem a tratar o público escolar como homogêneo", criando-se a tendência de normatizar a vida e deslocar para as histórias individuais os fracassos no processo de escolarização, chegando muitas vezes a atribuir ao estudante um diagnóstico que justifique o não aprender.

Corroborando com as discussões apresentadas e destacando a necessidade de atenção no encontro entre Saúde e Educação, Beltrame, \& Boarini (2013, p. 13) evidenciaram, em uma pesquisa realizada em um CAPSi de uma cidade do Paraná, a necessidade de atentar para os excessivos diagnósticos de crianças e adolescentes indicados com transtornos mentais, sendo que "estão incluídos nesses números muitos diagnósticos de transtornos questionáveis quanto a sua etimologia como doença". Tal constatação revela a importância do cuidado quanto às formas como se dão os encaminhamentos e diagnósticos dessas crianças e adolescentes.

Com relação ao público atendido pelo CAPSi, pesquisas têm demonstrado que considerável parte dos encaminhamentos são vinculados à escola (Beltrame, \& Boarini, 2013; Delfini, Dombi-Barbosa, Fonseca, Tavares, \& Reis, 2009), constatando-se que uma parcela deles são motivados por problemas relacionados à aprendizagem e ao comportamento no cotidiano escolar. Entre essas queixas, de acordo com Delfini et al. (2009, p. 232), em pesquisa realizada em São Paulo, encontraram-se situações de "dificuldade ou atraso de aprendizagem, falta de rendimento e de produtividade na escola bem como inadequação comportamental na escola, que envolvem comportamentos de rebeldia, agressividade, má conduta, agitação, hiperatividade, apatia e falta de participação".
Os alunos com comportamentos considerados inadequados em relação às normas e aos objetivos pré-estabelecidos nas escolas são marginalizados, sendo que "o fato de os objetivos da instituição escolar não alcançarem êxito acaba justificando a busca por parcerias em outros setores, como o CAPSi; todavia, o repensar das práticas escolares não é considerado nesse processo" (Beltrame, \& Boarini, 2013, p. 342).

Assim, entende-se que, por vezes, conforme já discutido, problemas do cotidiano são transformados em questões biológicas e individuais, fortalecendo desse modo o processo de medicalização, processo que tem como base uma ciência de matriz positivista, que move a sociedade de acordo com os interesses da classe dominante, naturalizando as desigualdades de modo a camuflar qualquer tipo de discriminação no alicerce do conhecimento científico (Collares, \& Moysés, 1996; Moysés, 2001). Historicamente, entende-se que esse movimento tem forte base e influência na sociedade brasileira, considerando que, em 1942, a Liga Brasileira de Higiene Mental ${ }^{2}$ difundia a seguinte proclamação: "a educação de uma criança deve sempre ser feita de um modo científico, e a família deverá sempre recorrer ao seu médico para que a oriente" (Brasil, 2005, p. 28).

Em outras palavras, o que se pretende não é negar ou deixar de reconhecer a importância do conhecimento científico, mas convocar os saberes constituídos, em especial o médico, psicológico e educacional, no questionamento das relações de produção, que promovem formas de viver e interpretar a vida.

Nesse sentido, a desconstrução do que está posto e naturalizado é plausível e encontra-se entre as possibilidades de atuação do CAPSi quando se coloca que, em casos em que se entender necessário, o serviço deverá intervir "junto a outras instâncias, a escola, por exemplo, quando encaminha situações de indisciplina ou os frequentíssimos 'problemas de aprendizagem' como se fossem questões de saúde mental que necessitassem de tratamento" (Brasil, 2005, p. 13).

Considera-se importante também destacar o diferencial de um tratamento que busque reconhecer "o sofrimento mental da criança ou do adolescente como próprios, o que não é a prática corrente,

\footnotetext{
${ }^{2}$ Entidade civil, composta pelos mais importantes psiquiatras brasileiros, fundada no Rio de Janeiro, em 1923, que tinha como objetivo primordial a melhoria na assistência aos doentes mentais, através da modernização do atendimento psiquiátrico. A partir de 1926, influenciados pelo contexto político e pelo contato com ideias alemãs, francesas e norte-americanas, os diretores da Liga mudaram sua orientação, de modo que uma clara tentativa de "normalizar" a população tornou-se o principal objeto para os médicos em seus esforços para inibir as pessoas com doença mental (Brasil, 2005).
} 
caracterizada por uma leitura moral em que o outro sempre fala pelo sujeito ao qual nunca se dá voz" (Brasil, 2005, p. 11).

Assim, a função social do atendimento do CAPSi vai além das atribuições técnicas, caminhando no sentido de "acolher, escutar, cuidar, possibilitar ações emancipatórias, melhorar a qualidade de vida da pessoa portadora de sofrimento mental, tendo-a como um ser integral com direito a plena participação e inclusão em sua comunidade" (Brasil, 2005, p. 14), sempre considerando as singularidades de cada sujeito, ampliando e reforçando os laços sociais dos usuários do serviço em instituições e grupos diversos. Desse modo, buscou-se apreender as concepções sobre adolescência e educação dos profissionais do CAPSi que embasam sua atuação, em especial aquela que se desenvolve junto ao processo de escolarização dos adolescentes que frequentam esse serviço.

Após exposto o que a literatura tem atualmente discutido sobre o tema estudado, o artigo será dividido em outras três partes: o caminho metodológico percorrido pela pesquisa, em sequência, a análise e discussão dos resultados e, por último, as considerações finais.

\section{Percurso metodológico}

Para que uma pesquisa caracterize-se como científica e para que produza um saber transformador, destaca-se a importância da definição de um referencial teórico-metodológico (Gatti, 2006). Dessa forma, adotou-se como base teórica a Psicologia Histórico-Cultural, que se fundamenta em alguns pressupostos do materialismo histórico dialético: sua concepção de homem, sociedade, realidade material e histórica.

Nessa perspectiva, entende-se o homem como um ser ativo, social e histórico. Assim, ao agir, ele se constitui e modifica o mundo e a si mesmo; marcado por uma cultura, ao transformar a realidade é ao mesmo tempo transformado. Em outras palavras, o homem se forma na dialética, "na relação de mediação com o social, relação em que homem e sociedade vivem a tensão constante de serem diferentes, opostos, mas de se constituírem mutuamente" (Aguiar, 2012, p. 59). Desse modo, o fenômeno estudado, por ser configurado na relação entre o homem e o mundo, poderá ser compreendido a partir de suas articulações, não sendo possível apreendê-lo de forma isolada, descolado da realidade social, cultural e econômica.

\section{Participantes}

O estudo aqui apresentado desenvolveu-se em um CAPSi de uma cidade da região norte do estado de Santa Catarina, que teve 11 de seus profissionais ${ }^{3}$ entrevistados, a saber: uma assistente social, um psiquiatra, duas psicólogas, duas enfermeiras, quatro terapeutas ocupacionais e a coordenadora do CAPSi. A escolha desses profissionais se deu por meio do contato inicial com a coordenadora do serviço, que os destacou como aqueles que assumiam maior responsabilidade em relação ao projeto terapêutico individual $^{4}$ dos adolescentes.

\section{Procedimento de coleta de dados}

O estudo teve como instrumento de coleta de dados a entrevista semiestruturada, elaborada de modo a responder ao objetivo da pesquisa. Essa entrevista “[...] ocorre quando as questões são previamente preparadas com um roteiro flexível que possibilite ganhar tempo e não repetir informações, mas que dá ao entrevistado a possibilidade de reflexão e revisão do que foi planejado" (Gonçalves, Baldin, Zanotelli, Carelli, \& Franco, 2008, p. 44). Nesse sentido, Lüdke \& André (1986, p. 33) acrescentam que "especialmente nas entrevistas não totalmente estruturadas, onde não há a imposição de uma ordem rígida de questões, o entrevistado discorre sobre o tema proposto com base nas informações que ele detém e que no fundo são a verdadeira razão da entrevista".

Para a realização da coleta de dados, inicialmente houve uma conversa com a coordenação do serviço, de modo a explicar os objetivos da pesquisa. Em seguida, verificou-se a disponibilidade de cada um dos profissionais de modo que as entrevistas foram realiza-

\footnotetext{
${ }^{2} \mathrm{O}$ quadro de profissionais no momento da pesquisa era composto por quatro terapeutas ocupacionais, quatro psicólogos (sendo que duas estavam afastadas), uma assistente social, dois enfermeiros, dois técnicos de enfermagem, cinco agentes administrativos, um psiquiatra e a coordenadora do CAPSi.

${ }^{4}$ Projeto terapêutico individual trata-se de um "conjunto de atendimentos que respeite a particularidade e personalize o atendimento de cada pessoa na unidade e fora dela e proponha atividades durante a permanência diária no serviço, segundo suas necessidades” (Brasil, 2004, p. 16).
} 
das individualmente em uma sala no próprio CAPSi. Todos os participantes foram previamente comunicados sobre os propósitos da pesquisa e participaram após "consentimento livre e esclarecido". Com a anuência dos participantes, as entrevistas foram gravadas e posteriormente transcritas.

\section{Aspectos éticos}

O Projeto de Pesquisa foi submetido à apreciação do Comitê de Ética em Pesquisa da Universidade da Região de Joinville (Univille) e aprovado pelo Parecer $\mathrm{n}^{\circ}$ 679.143, em 2 de junho de 2014. A pesquisa não apresentou riscos físicos aos participantes.

\section{Procedimento de análise dos dados}

A tessitura dos dados foi realizada a partir da análise de conteúdo, que se caracteriza por entender a linguagem "como uma construção real de toda a sociedade e como expressão da existência humana que, em diferentes momentos históricos, elabora e desenvolve representações sociais no dinamismo interacional que se estabelece entre linguagem, pensamento e ação" (Franco, 2008, p. 14).

Assim, a análise iniciou-se com a organização do material que foi dividido "em partes, relacionando essas partes e procurando identificar nele tendências e padrões relevantes. Num segundo momento essas tendências e padrões são reavaliados, buscando-se relações e inferências num nível de abstração mais elevado" (Lüdke, \& André, 1986, p. 45).

Em seguida, foram formuladas categorias, buscando identificar conteúdos manifestos e latentes do material, entendendo-se que a análise não deve se restringir ao que está explícito, procurando "ir mais a fundo, desvelando mensagens implícitas, dimensões contraditórias e temas sistematicamente 'silenciados"” (Lüdke, \& André, 1986, p. 48).

Por último, os dados foram categorizados e analisados do seguinte modo: concepção de adolescência nas vozes dos profissionais do CAPSi; profissionais do CAPSi e escola: entre a parceria possível e a parceria desejável; e função do CAPSi no processo de escolarização, conforme apresentado a seguir.

\section{Análise e discussão dos resultados}

\section{Caracterização do serviço investigado}

Para iniciar a análise dos dados, apresenta-se uma caracterização do serviço no qual se realizou a pesquisa. O CAPSi estudado atende ao público de 10 a 18 anos incompletos, que é organizado em grupos específicos de tratamento para usuários de substâncias psicoativas e para usuários com transtornos mentais. Desse modo, o CAPSi se organiza de forma a destinar dois dias da semana para o atendimento de transtornos mentais graves e dois dias da semana para $o$ atendimento de adolescentes que fazem uso e abuso de substâncias psicoativas, sendo um dia direcionado a reuniões de equipe, capacitação e formação.

Os encaminhamentos são realizados de maneira diferenciada também de acordo com a demanda do indivíduo. Os casos de uso e abuso de substância psicoativa são recebidos diretamente no CAPSi, já os casos de transtorno mental são encaminhados inicialmente para as regionais de saúde para uma primeira triagem, pois segundo Thais ${ }^{5}$ :

Em virtude de virem muitos encaminhamentos das escolas, [...] foi instituído esse protocolo, [...] em 2012, então a escola encaminha para regional de saúde, [...] se for um caso grave, que necessite desse cuidado intensivo diário, aí encaminha para o CAPSi.

Em geral, os atendimentos acontecem no contraturno da escola; e mesmo que haja alguns casos em que o atendimento seja realizado de forma integral e intensiva, no qual o adolescente tenha atenção todos os dias, o dia inteiro, Debora reforça que o trabalho é direcionado para: "Evitar a internação psiquiátrica, e ajudá-lo a retornar às atividades do cotidiano".

Há uma recomendação do trabalho interdisciplinar $^{6}$ quando se trata do cuidado da saúde mental de crianças e adolescentes e tal enfoque é adotado também no serviço estudado:

[...] dentro de um CAPS acho que não existe outra forma de trabalhar que não seja essa interdisci-

\footnotetext{
${ }^{5}$ Serão adotados nomes fictícios referentes às citações extraídas das transcrições das entrevistas.

${ }^{6} \mathrm{O}$ trabalho interdisciplinar permite um "enfoque ampliado dos problemas, recomendando-se a participação de médicos com experiência no atendimento infantil, psicólogos, enfermeiros, terapeutas ocupacionais, fonoaudiólogos, assistentes sociais, para formar uma equipe mínima de trabalho" (Brasil, 2004, p. 23).
} 
plinar, esse compartilhar saberes, dividir, trabalhar junto, eu acho isso muito enriquecedor, acho que tanto para os profissionais quanto para demanda atendida (Thais).

Para realizar os atendimentos, inicialmente os usuários participam de um acolhimento e são encaminhados a oficinas de grupo, conforme Maiara:

[...] no acolhimento, ele é orientado como que funciona o serviço [...]. Então, assim, a gente tenta repassar para eles o porquê que eles estão aqui no CAPSi realmente, da importância desse tratamento e não dessa obrigação. Porque muitas vezes eles só vêm porque o conselho tutelar mandou ou a mãe e o pai obrigaram.

Percebe-se que a cada trabalho desenvolvido valoriza-se a formação de vínculo da equipe com o paciente, visando à estruturação de um projeto terapêutico individual, que faça sentido para cada adolescente:

O principal objetivo no início do tratamento é a criação de vínculo, e aí a partir disso, estruturar um projeto terapêutico, que é o que ele queira também, porque se ele não tiver motivação para isso, a gente também não consegue nada (Debora).

\section{Concepção de adolescência nas vozes dos profissionais do CAPSi}

Uma primeira categoria destacada a partir da análise dos dados foi a concepção de adolescência, caracterizada nas vozes de alguns dos profissionais do CAPSi como uma etapa entre a infância e a idade adulta, adotando-se um padrão naturalizado que negligencia ser essa uma parte do desenvolvimento constituída e significada pela própria sociedade, o que induz ao apagamento da construção social e histórica das singularidades de cada adolescente que frequenta o serviço: "Acontecem várias modificações tanto hormonais quanto do comportamento, e acho que é mais essa fase de transição mesmo, que ele passa de ser criança para a fase adulta” (Anna).

[Na adolescência] se vivencia muitas mudanças, no próprio corpo, tanto na forma de pensar, de agir/ É, eu acho que é uma fase muito confusa para eles, porque várias coisas estão se transformando, estão acontecendo, e para eles fica difícil de lidar com essa situação (Gisela).

Em contraposição a essas concepções naturalizadas, aparece também nas falas dos profissionais do CAPSi o entendimento de que cada adolescente vive sua adolescência de forma única e singular: "[a adolescência] é a fase que eles se encontram ou desencontram, né?! Independente das alterações que a gente estuda, hormonais e tal... É diferente para cada um" (Daiani).

Apesar de a fala acima destacar a singularidade de cada um dos adolescentes que frequentam o CAPSi, é preciso mais do que esse entendimento para se trabalhar com uma perspectiva histórico-cultural, na qual o adolescente é entendido como "produto de sua história de vida, enquanto sujeito pertencente a um grupo social, a uma cultura, da qual recebe influência e sobre a qual age dialeticamente" (Fonseca, \& Ozella, 2010, p. 413).

Conhecer e refletir sobre as diferentes concepções de adolescência e suas raízes epistemológicas é fundamental para aqueles que trabalham com adolescentes com história de doença mental, pois, dependendo da concepção adotada, será formatada uma intervenção que discuta as condições de produção da saúde e da doença mental ou que endosse a individualização, a culpabilização e a vitimização daqueles que são encaminhados aos serviços de saúde mental.

\section{Profissionais do CAPSi e escola: entre a parceria possível e a parceria desejável}

Tendo em vista nossa sociedade escolarizada, a escola se torna fundamental no processo de humanização - em nosso contexto, é uma possibilidade de construção do sujeito enquanto ser humano, social e singular - bem como na constituição de sua identidade e inserção no meio social (Charlot, 2000). No entanto, a escola ocupa um lugar ambíguo na sociedade, uma vez que ao adotar um padrão hegemônico, ela pode também servir para legitimar as desigualdades sociais, desestimulando aqueles que apresentam alguma diferença em relação ao padrão de normalidade socialmente imposto, como é o caso dos adolescentes que frequentam o CAPSi.

Nas vozes dos profissionais do CAPSi, a escola assume um importante papel na formação do indivíduo, devendo ir além da transmissão de conteúdo: "É um espaço dinâmico de formação, de exercício da cidadania, de construção de direitos e deveres. 
Ela não deve ser só formação de conteúdo" (Caroline); "A escola tem uma função importante de socialização [...], acho que a escola também tem essa função, não só de transmitir conhecimento" (Natalie).

A escola, de forma geral, não lida bem com a diversidade, ela ainda prima pela homogeneidade. Os estudantes que têm uma necessidade diferenciada dificilmente encontram respaldo no processo de escolarização e isso fica evidente na fala de um dos profissionais do CAPSi: "É muito triste tu não conseguir estudar algo e alguém estar te cobrando e tu vai tirando nota baixa, é muito ruim, tu ver, tu vai criando um senso de incapacidade, de fracasso" (Daiani).

Nesse sentido, concorda-se com Moysés (2001, p. 48) quando destaca as consequências de uma história de fracasso no processo de escolarização, considerando que não é apenas na escola que o estudante se torna aquele que não sabe, a incapacidade adere a ele, "infiltra-se em todas as facetas, todos os espaços da vida. Deixa de ser incapaz na escola para se tornar apenas incapaz".

Essa situação se torna ainda mais crônica quando há o distanciamento entre o adolescente e a escola: "O fracasso vem de quando ele fica muito tempo distante, um, dois anos sem ir, e aí depois fica cada vez mais difícil o retorno deles" (Gisela).

Esse distanciamento da realidade escolar é grave, pois significa um "impedimento da apropriação do saber sistematizado, da construção de funções psicológicas mais sofisticadas, de instrumentos de atuação no meio social e de transformações dele e de condições para a construção de novos conhecimentos" (Rego, 2003, p. 35).

Em se tratando dos usuários do CAPSi, são vários os atores envolvidos no acompanhamento e nas ações que servirão de ancoragem para que esse adolescente tenha suporte para seu desenvolvimento. Nesse contexto, a família aparece como uma parceira importante no processo de escolarização do estudante.

A família, o apoio da família, o incentivo da família, [...] que tenha uma capacidade de entender a importância do estudo, de estar presente, a gente vê, esses não abandonam a escola (Jayne).

O desinvestimento da escola, da família e do próprio adolescente reforça a ideia, em nossa concepção, equivocada, de que não é viável investir na educação desses adolescentes.
Não foi acreditado nele, não foi visto ele [...]. Por isso que o fracasso na verdade é uma desistência, não é só o fracasso, é uma desistência, porque assim, "por que eu vou estudar? Eu não sei, eu não consigo, ninguém me ajuda, ninguém tá junto comigo, ninguém me vê"(Daiani).

Desse modo, para que seja possível a permanência e o retorno desse adolescente ao ambiente escolar, desconstruindo o sentimento de incapacidade assumido por ele (e aceito pela família e escola), e para que um novo lugar seja reconfigurado, é importante que se discuta como as condições sociais e culturais endossam a estigmatização daqueles que têm uma história de diagnóstico de doença mental.

\section{Função do CAPSi no processo de escolarização}

Para cada usuário do CAPSi é estabelecido um projeto terapêutico, no qual, a partir do vínculo criado com a equipe, torna-se possível compreender as necessidades dos adolescentes, buscando-se maneiras singulares para se trabalhar com eles. Nesse projeto, a escola é tida como uma ancoragem, assim, o retorno do adolescente ao ambiente escolar muitas vezes necessita de uma intervenção na qual os profissionais busquem parcerias com as escolas, estabelecendo contato por meio de conversas, orientações e reuniões relativas ao trabalho com o adolescente: "A gente senta com a escola, tenta ver com a escola, com a supervisão, coordenação, professores, enfim, maneiras de trazer aquele adolescente pra escola de novo" (Jayne).

Os profissionais relatam os desafios com que se deparam quando se trata do retorno do adolescente para a escola e da necessidade de mostrar outras possibilidades existentes, além do ensino regular, conforme exemplificado por Caroline: "Não só na educação formal, mas em cursos profissionalizantes e outras formas de aprendizagem, não só no ensino regular".

Algo que os profissionais têm trabalhado com os adolescentes que frequentam o CAPSi é o seu projeto de vida, e conversam, também, sobre a importância de $o$ adolescente estudar:

Isso a gente faz [trabalhar a importância de estar estudando]. Tem grupos que trabalham projeto de vida, mas o adolescente precisa estar no momento certo para poder trabalhar isso, então 
não são todos que estão no momento certo para trabalhar projeto de vida (Jeniffer).

[trabalhar com o projeto de vida é importante para que o adolescente] entenda o papel que a escola vai ter na vida dele [...]. Ele começa a ter uma percepção do que essa escola realmente pode fornecer para ele (Maiara).

[No trabalho com o projeto de vida] a gente meio que orienta, tenta mostrar que eles não são fracassados (Daiana).

Assim, ao levar em consideração a situação de fracasso do estudante, deve-se observar não apenas a falta, mas todos os fatores envolvidos no processo de escolarização do sujeito (Charlot, 2000). Percebe-se, desse modo, o trabalho diferenciado que pode ser realizado quando os setores da educação e da saúde se unem para o desenvolvimento de ações que envolvem a saúde mental de crianças e adolescentes.

\section{Considerações finais}

O estudo realizado evidenciou que a atuação dos profissionais do CAPSi investigado ainda se encontra pautada em uma concepção naturalizada de adolescência, mesmo em uma equipe que avança na direção de um trabalho que busca articular sua atuação não só ao adolescente, mas a diferentes esferas da vida, tais como a família e a escola.

Construir o trabalho com crianças e adolescentes que têm um histórico de diagnóstico de doença mental e/ou fazem uso de substâncias psicoativas dentro de uma abordagem que contemple o entendimento da constituição humana por meio das relações sociais amplia as possibilidades de propor ações, bem como de questionar como são construídas as trajetórias daqueles que chegam até o CAPSi.

Adotar uma concepção de adolescência e educação dentro de uma perspectiva biologicista, naturalizante e descolada do contexto em que cada um desses adolescentes se constituiu facilita a aderência a abordagens que atribuam a incapacidade, a doença e o estigma ao adolescente de forma individualizada. Assim percebe-se a importância de ampliar os estudos que contemplem o encontro entre saúde e educação para que cada vez mais se evidencie possibilidades de um trabalho que efetivamente implique uma reflexão de como a escola, a família e as demais estruturas sociais podem convergir para uma história de doença mental ou não, isto é, de como as relações sociais são potentes em favor da construção de possibilidades de aprendizagem e desenvolvimento ou de estigmatizar e adoecer.

\section{Referências}

Aguiar, W. M. J. (2012). Armadilhas e alternativas nos processos educacionais e na formação de professores: uma análise na perspectiva da psicologia sócio-histórica. In M Jacó-Vilela, \& L Sato, Diálogos em psicologia social (pp. 58-70). Rio de Janeiro: Centro Edelstein de Pesquisas Sociais.

Alves, N., \& Canário, R. (2004). Escola e exclusão social: das promessas às incertezas. Análise Social, 38(169), 981-1010. Recuperado de http://analisesocial.ics.ul.pt/documentos/1218650678S9rNN2al1Cx82TV2.pdf

Beltrame, M. M., \& Boarini, M. L. (2013). Saúde mental e infância: reflexões sobre a demanda escolar de um CapSi. Psicologia, Ciência e Profissão, 33(2), 336-349. http://dx.doi.org/10.1590/S1414-98932013000200007

Bock, A. M. B. (2007). Adolescência como construção social: estudo sobre livros destinados a pais e educadores. Revista Semestral da Associação Brasileira de Psicologia Escolar e Educacional, 11(1), 63-76. http://dx.doi.org/10.1590/S1413-85572007000100007

Brasil. (2005). Ministério da Saúde. Caminhos para uma política de saúde mental infanto-juvenil. Brasília, DF: o autor. (Série B. Textos básicos em saúde).

Brasil. (2002). Ministério da Saúde. Portaria GM No 336, de 19 de fevereiro de 2002. Define e estabelece diretrizes para o funcionamento dos Centros de Atenção Psicossocial. Brasília, DF: o autor.

Brasil. (2011, 26 de dezembro). Ministério da Saúde. Portaria No 3.088, de 23 de dezembro de 2011. Institui a Rede de Atenção Psicossocial para pessoas com sofrimento ou transtorno mental e com necessidades decorrentes do uso de crack, álcool e outras drogas, no âmbito do Sistema Único de Saúde (SUS). Diário Oficial da União.

Brasil. (2004). Ministério da Saúde. Saúde mental no SUS: os centros de atenção psicossocial. Brasília, DF: o autor. 
Canário, R. (2004). Territórios educativos e políticas de intervenção prioritária: uma análise crítica. Perspectiva, 22(1), 47-78. Recuperado de https://periodicos.ufsc.br/index.php/perspectiva/article/view/ 10082

Charlot, B. (2000). Da relação com o saber: elementos para uma teoria. Porto Alegre. RS: Artmed.

Collares, C. A. L., \& Moyses, M. A. A. (1996). Preconceitos no cotidiano escolar: ensino e medicalização. São Paulo, SP: Cortez.

Couto, M. C. V., \& Delgado P. G. G. (2015). Crianças e adolescentes na agenda política da saúde mental brasileira: inclusão tardia, desafios atuais. Psicologia Clinica, 27(1), 17-40. https://doi.org/10.1590/0103-56652015000100002

Delfini, P. S. S., Dombi-Barbosa, C., Fonseca, F. L., Tavares, C. M., \& Reis, A. O. A. (2009). Perfil dos usuários de um centro de atenção psicossocial infanto-juvenil da grande São Paulo, Brasil. Revista Brasileira de Crescimento e Desenvolvimento Humano, 19(2), 226-236. Recuperado de http://pepsic.bvsalud.org/scielo.php?script=sci_ arttext\&pid=S0104-12822009000200004\&lng=pt\&nrm=iso\&tlng=pt

Fonseca, D. C., \& Ozella, S. (2010). As concepções de adolescência construídas por profissionais da Estratégia de Saúde da Família (ESF). Interface (Botucatu), 14(33), 411-424. https://doi.org/10.1590/S1414-32832010000200014

Franco, M. L. P. B. (2008). Análise do conteúdo. Brasília, DF: Liber livro.

Gatti, B. A. (2006). Pesquisa em educação: considerações sobre alguns pontos-chave. Revista Diálogo Educacional, 6(19), 5-35.

Gonçalves, M. L., Baldin, N., Zanotelli, C. T., Carelli, M. N., \& Franco, S. C. (2008). Fazendo pesquisa: do projeto à comunicação científica. Joinville, SC: Univille.

Lüdke, M., \& André, M. (1986). Pesquisa em educação: abordagens qualitativas. São Paulo: EPU.

Martins, J. S. (2003). Exclusão social e a nova desigualdade. São Paulo: Paulus.

Meira, M. E. M. (2003). Construindo uma concepção crítica de psicologia escolar: contribuições da pedagogia histórico-crítica e da psicologia sócio-histórica. In M. E. M. Meira, \& M. A. M. Antunes, Psicologia escolar: teorias críticas. São Paulo, SP: Casa do Psicólogo.

Meletti, S. M. F. (2013). Diferenças e diferentes: aspectos psicossociais da deficiência. In S. M. F. Meletti, M. C. \& M. Kassar, Escolarização de alunos com deficiências: desafios e possibilidades (pp. 13-31). Campinas, SP: Mercado das Letras.

Moysés, M. A. A. (2001). A institucionalização invisível: crianças que não-aprendem-na escola. Campinas, SP: Mercado de Letras.

Ozella, S. (2002). Adolescência e psicologia: concepções, práticas e reflexões críticas. In Conselho Federal de Psicologia, Adolescência: uma perspectiva crítica (pp. 16-24). Brasília, DF: o autor.

Ozella, S., \& Aguiar, W. M. J. (2008). Desmistificando a concepção de adolescência. Cadernos de Pesquisa, 38(133), 97-125. https://doi.org/10.1590/S0100-15742008000100005

Rego, T. C. (2003). Memórias de escola. Petrópolis, RJ:Vozes.

Veiga-Neto, A., \& Lopes, M. C. (2011). Inclusão, exclusão, in/exclusão. Verve, (20), 121-135. Recuperado de http://revistas.pucsp.br/index.php/verve/article/view/14886

Vicentin, M. (2006). Infância e adolescência: uma clínica necessariamente ampliada. Revista de Terapia. Ocupacional da Universidade de São Paulo, 17(1), 10-17. https://doi.org/10.11606/issn.2238-6149.v17ilp10-17

Heloiza Iracema Luckow

Graduação em Psicologia pela Universidade da Região de Joinville - Univille, Joinville - SC, Brasil.

E-mail: helo_luckow@hotmail.com

\section{Aliciene Fusca Machado Cordeiro}

Doutorado em Educação (Psicologia da Educação) pela Pontifícia Universidade Católica de São Paulo (2006). Professora-pesquisadora da Universidade da Região de Joinville - Univille Joinville - SC, Brasil.

E-mail: aliciene_machado@hotmail.com 
Endereço para envio de correspondência:

Universidade da Região de Joinville.

Paulo Malschitzki, 10 Campus Universitário. Zona Industrial. CEP: 89219-710.- Joinville - SC, Brasil.

Recebido 20/04/2016

Reformulação 12/09/2016

Aprovado 13/02/2017

Received 04/20/2016

Reformulated $09 / 12 / 2016$

Approved 02/13/2017

Recebido 20/04/2016

Reformulado 12/092016

Aceptado 13/02/2017

Como citar: Luckow, H. I., \& Cordeiro,A. F. M. (2017). Concepções de adolescência e educação na atuação de profissionais do CAPSi. Psicologia: Ciência e Profissão, 37(2), 393-403. https://doi.org/10.1590/1982-370301432016

How to cite: Luckow, H. I., \& Cordeiro, A. F. M. (2017). Conceptions of adolescence and education in the professional practice of CAPSi. Psicologia: Ciência e Profissão, 37(2), 393-403.

https://doi.org/10.1590/1982-370301432016

Cómo citar: Luckow, H. I., \& Cordeiro, A. F. M. (2017). Concepciones de adolescencia y educación en la actuación deprofesionalesdelCAPSi.Psicologia:CiênciaeProfissão,37(2),393-403.https://doi.org/10.1590/1982-370301432016 